\title{
Development of the Hand Operated Granular applicator for Creeper Crops
}

\author{
M. Sai Srinivas", B. Raj Kiran, B. Sailaja and M.M. Krishna \\ College of Agricultural Engineering, Bapatla - 522101, ANGRAU, Andhra Pradesh, India \\ *Corresponding author
}

\section{A B S T R A C T}

\begin{tabular}{|l|}
\hline Ke y w o r d s \\
Distributor, \\
Applicator, \\
$\begin{array}{l}\text { Fertilizer granules, } \\
\text { Creeper crops. }\end{array}$ \\
\hline Article Info \\
\hline $\begin{array}{l}\text { Accepted: } \\
28 \text { October } 2017 \\
\text { Available Online: } \\
\text { 10 December } 2017\end{array}$ \\
\hline
\end{tabular}

Improper and inaccurate application of fertiliser causes abnormal and non-homogeneous soil fertility which is against to the objective of precision agriculture. As the conditions and land holdings are small and fragmented, power operated distributors are efficient but may result in wastage of power fertiliser granules due to its treatment away from the concentrated area. Initial purchase cost is high. Hence it is not affordable to small and medium scale farmers. Power operated applicator may not have versatility in spreading. The study is concerned on fertilizer application for creeper crops, where intercultivated equipment may not able to manure between the crop rows for fertilizer application. Even conventional manual dropping of fertilizer may also cause drudgery due to continuous bending during application at the root zone. This Paper suggests the hand operated applicator which is affordable for small scale farmers can drop and distribute the fertiliser in equal amount at concentrated area i.e. at the root zone there by reducing the wastage of fertiliser and drudgery. Maximum thrust is given for the application of gourd crops, cucumbers and other creeper crops.

\section{Introduction}

Precision agriculture is an emerging technology for improving crop production inputs like fertilizer, herbicide, seed, and etc. Farmers practicing precision farming may experience the enhanced quality and quantity of their products due to better adjustment of production inputs to crop needs. One of the objectives in the precision agriculture is correct quantity and depth of application plays a major role. The objective of a fertilizer application can be summed up with a single sentence. "Put the right product on the right target at the right time". The increase of the rate of fertilizer generally increases the crop yield up to an optimum level, but extra fertilizer is less utilized or mobilized. Granular fertilizers need to be delivered at the prescribed application rates to accomplish the desired outcome of correcting within-field variations in plant nutrients. Granular applicator is a machine that applies granular fertiliser, pesticide, such as slug pellets or Avadex or insecticide. Granular applicators are used for precision application of solids to improve crop yields and quality. Application rates are often controlled electronically to improve accuracy (Derborg et al., 2012). Generally Manually operated granular applicators is very much suitable to apply fertiliser to Cucurbits, which include cucumbers, muskmelons, watermelons, pumpkins, summer squash, winter squash, and gourds, are some of the most popular garden vegetables planted now a days. 


\section{Materials and Methods}

The following points were taken into consideration for designing hand operated granular applicator.

No. of flutes.

Diameter of flute.

Depth of the flute.

The equipment should be simple in construction.

It should have simple and easy adjustment.

It should have uniformity in dropping of GU.

It should be made with locally available materials with simple technology \& versatility (distributor and drop application).

It should be easy to repair and maintain.

The cost of machine must be within the capacity of small and medium farmer.

It should be light in weight and easy to operate.

It should be suitable for operating by a single person.

\section{Selection of hopper}

Fertilizer hoppers can be rectangular, trapezoidal and cylindrical. The selection of hopper depends up on the density, angle of repose and various other parameters. A frustum shaped trapezoidal hopper was selected. The hopper was designed to carry a weight of $5 \mathrm{~kg}$ in one fill.

Volume of the Frustum of a Right circular cone $(\mathrm{V})=^{\frac{1}{3} \pi h\left(r^{2}+R r+R^{2}\right)}$

\section{Quantity of fertilizer required per plant}

For creeper crops such as cucumber and gourds the general spacing row to row, plant to plant maintained from 1 to $1.5 \mathrm{~m} \& 0.5$ to $0.75 \mathrm{~m}$ respectively.

Farmers recommended spacing of $1.3 \times 0.6^{\mathrm{m}^{2}}$ was selected. Number of plants per acre was calculated in general practices of farmers for cucumbers and gourds. An amount of $80 \mathrm{kgs}$ per acre can be applied in two treatments.

Hence under these conditions, the weight of granules per plants was calculated based on the following equations.

Recommended spacing is $1.3 \times 0.6$ sq.m

Number of plants/acre $=\frac{\text { Area }}{\text { Spacing }}$.

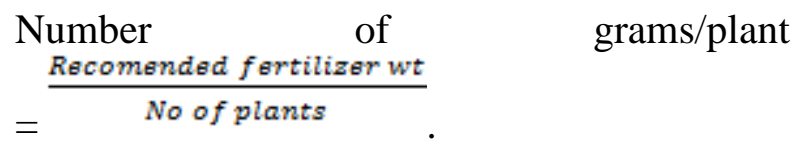

\section{Design consideration for a fluted roller}

Diameter of the roller, radius of the flutes and length of the flutes were designed from the basic formulae given below. The flutes were considered in the shape of the semi-circle.

Volume of one flute $=\frac{\frac{\pi}{8}}{8} d^{2}$ L (4)

Where $\mathrm{d}=$ diameter of the one flute $(\mathrm{cm}), \mathrm{L}=$ length of the flute $(\mathrm{cm})$

\section{Design calculations}

$$
\begin{aligned}
& \frac{4048}{1.3 \times 0.6}=5190 \text { plants } \\
& \frac{40 \times 1000}{5190}=7.9 \mathrm{gms}=8 \mathrm{gm} \text { (Approx) }
\end{aligned}
$$




\section{Selection of hopper}

Volume of the Frustum of a Right circular cone $\left.={ }^{\frac{1}{3} \pi h\left(r^{2}\right.}+\mathrm{Rr}+{ }^{R^{2}}\right)$

By trial and error, the obtained dimensions are

Height of the cone $=20 \mathrm{~cm}$

Radius of the upper base $=8 \mathrm{~cm}$

Radius of the lower base $=12.5 \mathrm{~cm}$

Then, volume of the hopper $=0.0067 \mathrm{cu} . \mathrm{m}$

Bulk density of the urea: $715-770 \mathrm{~kg} / \mathrm{sq} \cdot \mathrm{m}$

$1 \mathrm{cu} \cdot \mathrm{m}=750 \mathrm{~kg}$

0.0067 cu.m $=--$

Obtained hopper capacity $=5 \mathrm{~kg}$

\section{Calculations for fluted roller}

Volume of the semi-circle $={ }^{\frac{\pi}{8}} d^{2}{ }_{1}$

By trial and error method the dimensions are

Diameter of flute $=1 \mathrm{~cm}$

Length of the flute $=5.5 \mathrm{~cm}$

Diameter of the roller $=5.3 \mathrm{~cm}$

By substituting this, volume $=2.15 \times^{10^{-6}}$ cu.m

1 cu.m $=750 \times 1000$ gms

$2.15 \times^{10^{-6}}$ cu.m $=----$

The obtained volume is $1.6 \mathrm{gms}$
For determining number of flutes in the roller, $=8 / 1.6=5$ no. of flutes.

\section{Construction and working principle of GU applicator}

The applicator consists of various parts such as hopper, metering box, fluted roller, hand crank, hoes pipes and back mounted frame for dropping applicator.

A part from this an additional attachment i.e. distribution applicator (motor, fan and cone etc.) was connected at the end of the discharge hoes pipe for distributing granules around the plant root zone.

Applicator was designed for $5 \mathrm{~kg}$ capacity of granular fertilizer. Recommended fertilizer meters from the hopper to the plant root zone through the metering box by gravity. One end of the metering box is connected to hopper by hoes pipe, and then other end is kept open for discharging of fertilizer. The metering box consists of fluted roller which gets its drive by rotating the hand crank. Quantity of fertilizer dropping from the hopper to metering unit was regulated by feed gate and in turn the application rate was regulated by number of rotations of fluted roller. The amount of metered fertilizer depends upon the number, width and depth of the exposed flutes, and the speed of rotation of the metering rotor. Fluted roller metering system was used in this hand operated granular applicator.

\section{Components}

\section{Fabrication of wooden fluted roller}

After the lathe operation the centre diameter was divided for 5 flutes. Finally a $6 \mathrm{~mm}$ hole was made at its centre to insert a shaft in to the roller. The main function of fluted roller is to meter correct quantity of fertilizer per revolution. 
Fig.1 Selection of hopper

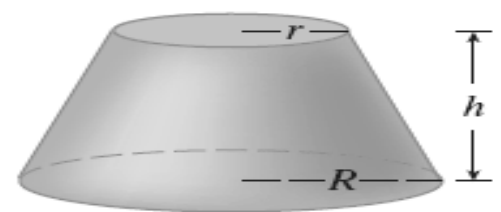

Fig.2 The overall view of Hand operated granular applicator

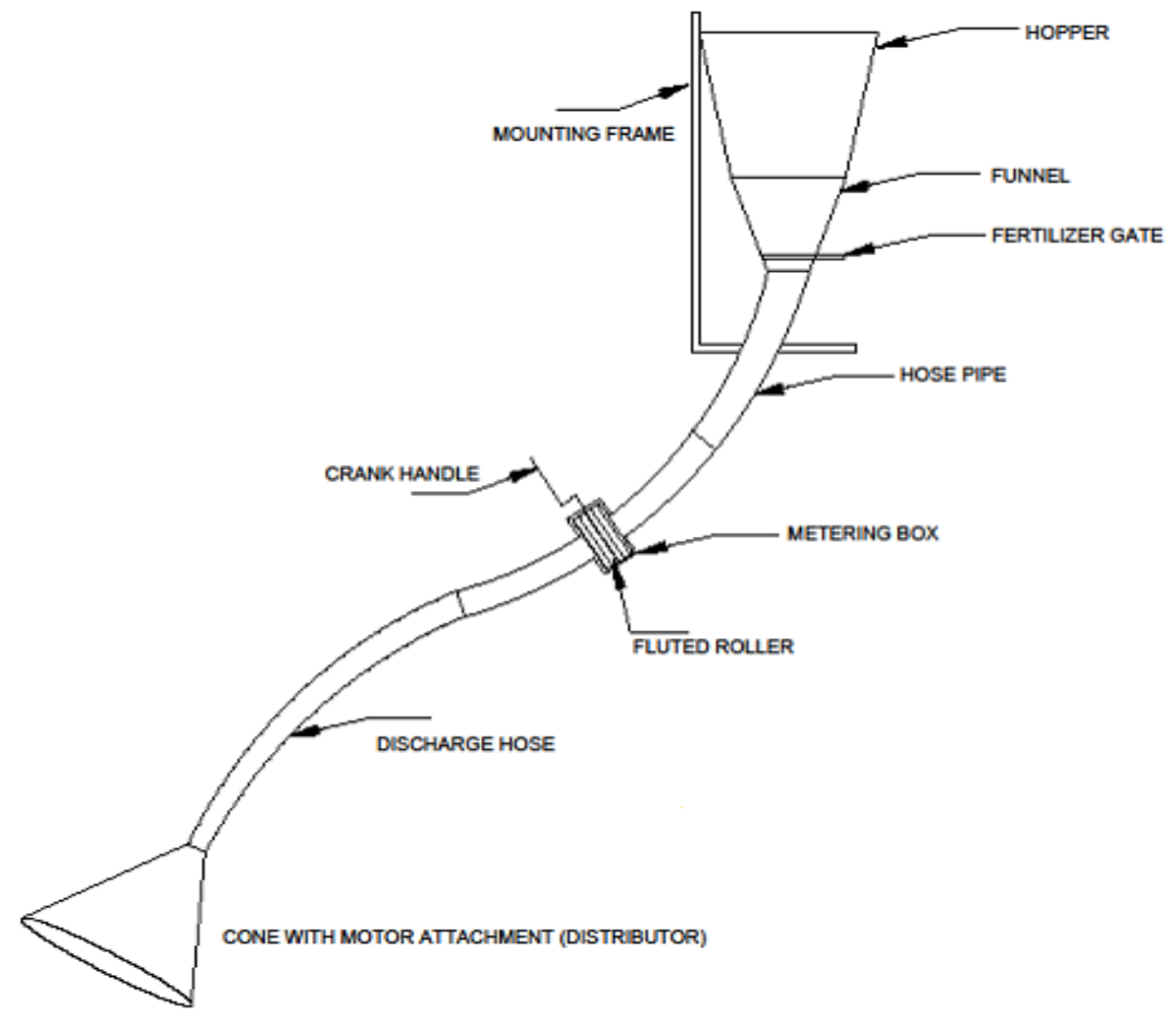

Fig.3 Designed fluted roller

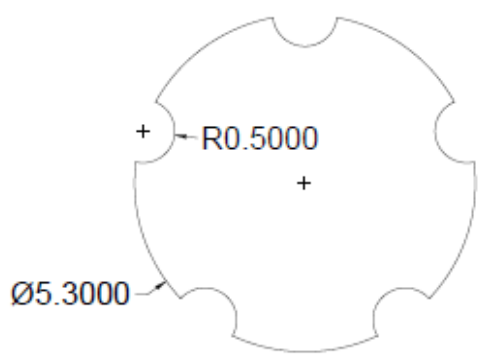


Fig.4 Developed fluted roller

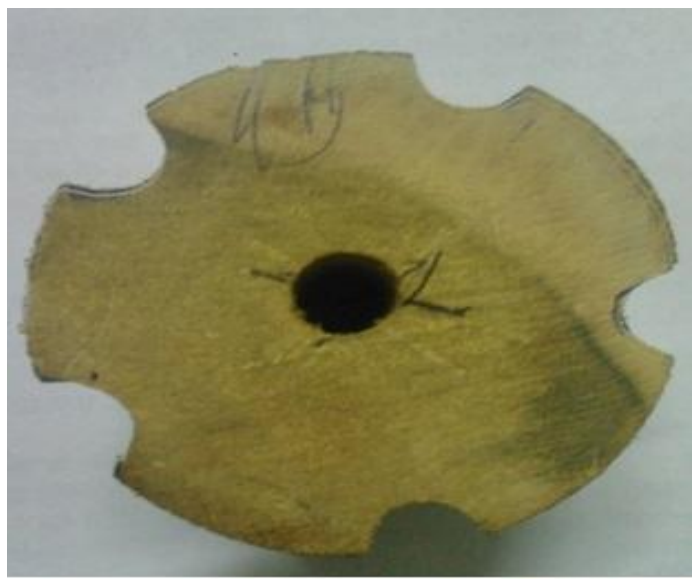

Fig.5 Designed view of flute periphery

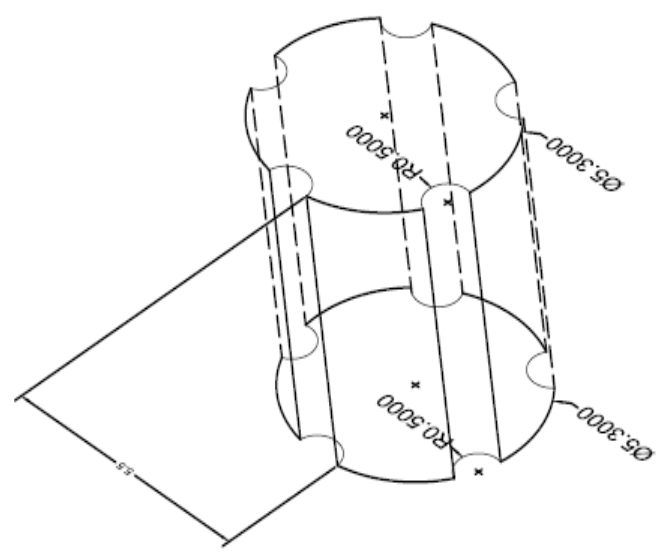

Fig.6 View of flute throughout its periphery

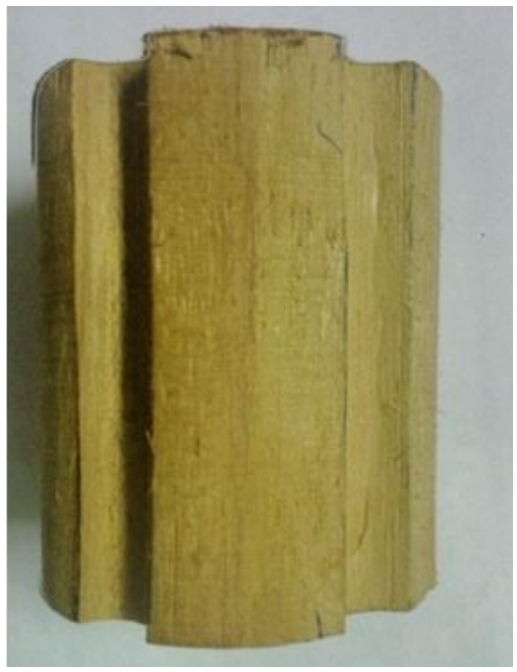


Fig.7 MS plate with bearing

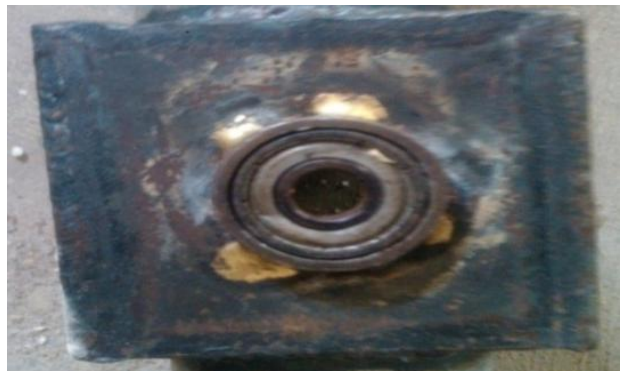

Fig.8 Fluted roller metering box

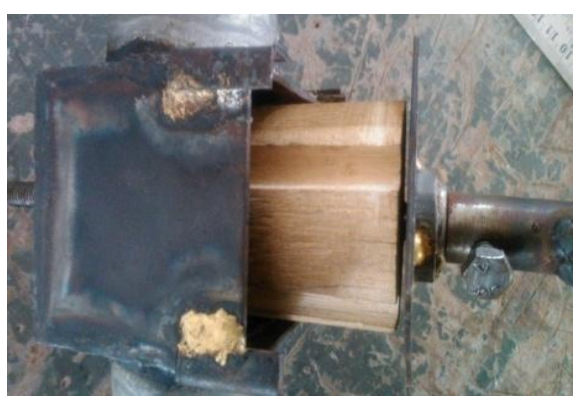

Fig.9 Metering box assembly attached with GI pipes

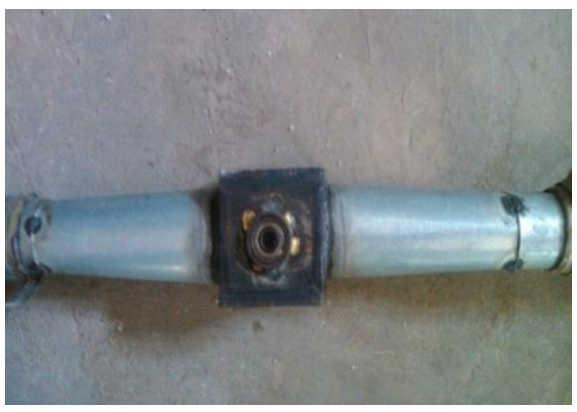

Fig.10 Developed Hand operated granular applicator

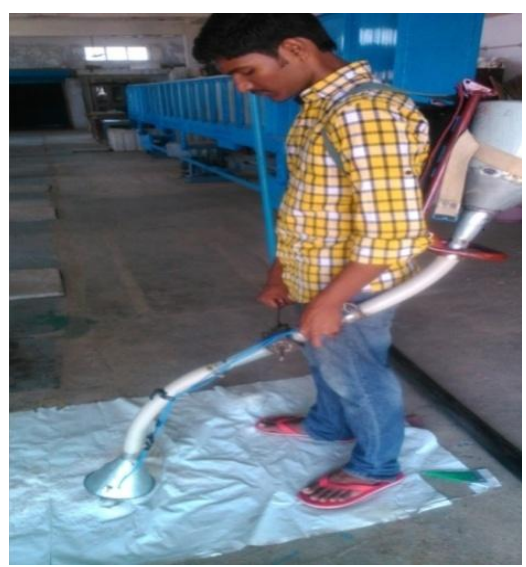


Table.1 Descriptive statistics of weight of GU

\begin{tabular}{lc}
\hline Statistical parameter & Statistical results of measured data, unit \\
\hline Mean $(\mathrm{gm})$ & 9.06 \\
Median $(\mathrm{gm})$ & 8 \\
Mode $(\mathrm{gm})$ & 8 \\
Coefficient of variation & 0.617 \\
Minimum collected fertilizer $(\mathrm{gm})$ & 7 \\
Maximum collected fertiliser $(\mathrm{gm})$ & 12 \\
Range $(\mathrm{gm})$ & 5 \\
\hline
\end{tabular}

Table.2 Determination of Mean fertiliser quantity dropped for drop application

\begin{tabular}{ccccc}
\hline S. No & $\begin{array}{c}\text { No. of } \\
\text { revolutions }\end{array}$ & $\begin{array}{c}\text { Theoretical quantity } \\
\text { required to drop (gms) }\end{array}$ & $\begin{array}{c}\text { Quantity } \\
\text { dropped (gms) }\end{array}$ & $\begin{array}{c}\text { Over falling rate } \\
(\%)\end{array}$ \\
\hline 1 & 5 & 40 & 42.67 & 6.67 \\
2 & 10 & 80 & 83.67 & 4.58 \\
3 & 15 & 120 & 123.33 & 2.67 \\
\hline
\end{tabular}

Table.3 Determination of Mean fertiliser quantity drop for distributor application

\begin{tabular}{cccc}
\hline S. No & No. of revolutions & Quantity dropped(kg) & Over falling rate (\%) \\
\hline 1 & 5 & 44 & 10 \\
2 & 10 & 85.3 & 6.67 \\
3 & 15 & 123 & 2.49 \\
\hline
\end{tabular}

Table.4 Discharge rate for drop application

\begin{tabular}{cccccc}
\hline $\begin{array}{c}\text { Time } \\
(\mathrm{min})\end{array}$ & $\begin{array}{c}\text { No. of } \\
\text { revolutions }\end{array}$ & $\begin{array}{c}\text { Fertiliser } \\
\text { filled in } \\
\text { hopper(kg) }\end{array}$ & $\begin{array}{c}\text { Fertiliser left in } \\
\text { hopper }(\mathrm{kg})\end{array}$ & $\begin{array}{c}\text { Quantity } \\
\text { dropped } \\
(\mathrm{kg})\end{array}$ & $\begin{array}{c}\text { Over } \\
\text { falling } \\
\text { rate }(\%)\end{array}$ \\
\hline 1 & 40 & 5 & 4.656 & 0.344 & 7.50 \\
1 & 52 & 5 & 4.560 & 0.440 & 5.76 \\
1 & 44 & 5 & 4.636 & 0.364 & 3.40 \\
Avg & 45 & 5 & 4.617 & 0.382 & 5.55 \\
\hline
\end{tabular}

Table.5 Discharge rate for distributor application

\begin{tabular}{cccccc}
\hline $\begin{array}{c}\text { Time } \\
(\mathrm{min})\end{array}$ & $\begin{array}{c}\text { No. of } \\
\text { revolutions }\end{array}$ & $\begin{array}{c}\text { Fertiliser } \\
\text { filled in } \\
\text { hopper }(\mathrm{kg})\end{array}$ & $\begin{array}{c}\text { Fertiliser left in } \\
\text { hopper }(\mathrm{kg})\end{array}$ & $\begin{array}{c}\text { Quantity } \\
\text { dropped } \\
(\mathrm{kg})\end{array}$ & $\begin{array}{c}\text { Over } \\
\text { falling } \\
\text { rate }(\%)\end{array}$ \\
\hline 1 & 62 & 5 & 4.512 & 0.488 & 2.410 \\
1 & 51 & 5 & 4.580 & 0.420 & 2.850 \\
1 & 43 & 5 & 4.650 & 0.350 & 1.744 \\
Avg & 45 & 5 & 4.580 & 0.419 & 2.330 \\
\hline
\end{tabular}


Table.6 Actual field capacity

\begin{tabular}{ccc}
\hline S. No. & $\begin{array}{l}\text { Time taken to cover an } 100 \\
m^{2} \text { area in } \min \end{array}$ & $\begin{array}{c}\text { Actual field capacity, ha/hr (area } \\
\text { /time) }(\mathrm{ha} / \mathrm{hr})\end{array}$ \\
\hline 1 & 4.09 & 0.1466 \\
\hline
\end{tabular}

\section{Fabrication of metering box}

The six number of $3 \mathrm{~mm}$ thick MS Sheets were cut in to $6 \times 6 \mathrm{~cm}$ size with the help of shearing machine.

Roller bearings were inserted in to two faces and GI pipes were welded to the remaining two plates for connecting to hoes pipes. The metering box confines the fertilizer to fall on the fluted roller.

\section{Hopper}

Required size of hopper for carrying $5 \mathrm{~kg}$ of fertilizer was selected and the small funnel was welded at the lower side of hopper for easy flow of granular material to the discharge hoes.

Since the angle of repose of urea fertilizer was $27^{\circ}$, the included angle of funnel was selected as $120^{\circ}$.

\section{Hand crank and distributor}

The $6 \mathrm{~mm}$ diameter shaft of length of $12 \mathrm{~cm}$ was drilled in to the metering roller and one end of the shaft was welded with crank handle. This crank handle assists in rotating fluted roller for metering the fertilizer as shown in figure 2 .

An additional attachment was provided at the end of the drop applicator hoes for distributing the metered quantity of fertilizer. Cone provided over the circumference of the blade to restrict the distribution of fertilizer away from concentrated area. The complete setup of distributor is shown in the figure 2 .
Performance evaluation of granular applicator

Performance evaluation was done for weight of Granular urea, Discharge rate in laboratory and theoretical field capacity, actual field capacity, field efficiency.

\section{Laboratory experiment}

\section{Determination of the weight of granular urea}

Handle of metering unit was rotated for 1 revolution and the weight of collected urea was measured under electrical weigh balance.

From the above table 1 it was observed that mean weight of the sample collected for fifteen replications is $9.06 \mathrm{gm}$, which is almost nearer to the designed value of dropping (8gm).

The coefficient of variance was observed as 0.617 which is negligible with good uniformity of fertilizer dropping. The minimum and maximum fertilizer collected were $7 \mathrm{gm}$ and $12 \mathrm{gm}$ respectively where this amount may vary in the range of $5 \mathrm{gm}$.

\section{Percent missing by drop and distributor applications}

Different trails were conducted for checking the suitability of metering system for drop and distributor applicator as shown in table 2 and table 3 respectively. The actual quantity dropped for 5, 10 and 15 revolutions are more than the designed dropping/revolution (8gm). This is due to the clearance between the roller 
and metering box. The mean over falling rate is decreased, as the no of revolutions increased; this may be due to, at lower revolutions the bulk amount of material comes in contact with roller and even there is some leakage of material without any crank revolution and at higher revolutions the amount of dropping is compensated by the slippage of conveying the material from roller to discharge tube.

The discharge rate was calculated by taking different no of revolutions in a min. The average discharge rate calculated as 22.92 $\mathrm{kg} / \mathrm{hr}$.

The discharge rate was calculated by taking different no of revolutions in a min. The average discharge rate calculated as 25.14 $\mathrm{kg} / \mathrm{hr}$.

\section{Field test}

Performance evaluation was done for its theoretical field capacity, actual field capacity, field efficiency.

\section{Theoretical field capacity}

Theoretical field capacity of Hand operated Granular applicator value was found to be $0.26 \mathrm{ha} / \mathrm{hr}$.

\section{Actual field capacity}

It is the actual rate of coverage of area by hand operated granular applicator. Its value was found to be $0.1466 \mathrm{ha} / \mathrm{hr}$ (Table 6).

\section{Field efficiency}

The field efficiency of Hand operated granular applicator was calculated by taking the value of actual field capacity and theoretical field capacity and it was to be $56.38 \%$.

\section{Cost economics}

The cost of operation of Hand operated granular applicator was calculated by knowing its fixed costs and operating costs. Hectare covered per year $=0.1466 \mathrm{ha} / \mathrm{hr} \mathrm{X}$ $250 \mathrm{hr}=36.65 \mathrm{ha}$. Cost of operation /ha. = 284.24 Rs /ha.

The applicator was developed for its versatility to drop and distribute to granules with uniform quality at the plant root zone. An additional attachment distributor (motor, blades, and cone) was provided at lower portion of the applicator. The applicator can be converted to drop and distribution application depending on necessity. These applicators were developed for creeper crops.

The developed drop applicator was evaluated for its performance under laboratory and field conditions. Laboratory tests were conducted to check the suitability of metering unit. Under this test the amount of percent over flow were calculated for both drop and distributor applicator was found to be 6.67, 4.58, and 2.67 percent for 5, 10 and 15 revolutions of roller. The over falling rate is decreased, as the no of revolutions increased for both drop and distributor applicator. The coefficients of variations of different droppings were calculated as 0.617. Theoretical field capacity, Actual field capacity, Field efficiency of Hand operated granular applicator was $0.26 \mathrm{ha} / \mathrm{hr}$, $0.1466 \mathrm{ha} / \mathrm{hr}, 56.38 \%$ respectively. The average discharge rate was found to be 156 $\mathrm{kg} / \mathrm{ha}$ and $171 \mathrm{~kg} / \mathrm{ha}$ for drop and distributor application respectively.

\section{References}

Ahamed, M.S., Ziauddin, A.T.M. and Sarker, R.I. 2014. Design of improved urea super granule applicator. Int. Journal of Applied Sciences and Engineering Research. 3(1): 98-104. 
Ahmed, M.R., Billah, M.M. and Ziauddin, A.T.M. 2012. Battery Operated USG Applicator Progress. Agric. 23(1 \& 2): 75 -80 .

Ajoy kundu. 2014. Design and Development of a Pull Type Four Rows Granular Urea Applicator. Department of farm power and machinery, Bangladesh agricultural university.

Alam, A. and Sarker, T.R. 2014. Performance evaluation of a pull type two rows granular urea applicator. J. Bangladesh Agril. Univ. 12(1): 211-220.

Alireza, S. and Sheikhdavoodi, M.J. 2012. Evaluating of Broadcasting Uniformity of Centrifugal and Oscillating Granular Broadcasters. Research Journal of Applied Sciences, Engineering and Technology. 4(15): 2460-2468.

Angel, P.G., Nelson, L.C. and Claudio, K.U. 2012. Auger-Type Granular Fertiliser Distributor Mathematical Model and Dynamic Simulation. Eng. Agric. 32 (1):151-163.

Derborg, MenoBot and AnaBykov. Granular applicator. Text and image sources, contributors and licenses. 4:1-2

Drever, K.W. and Wiens, E.H. 1979. Granular Herbicide Applicator. Testing American society of Agricultural engineers. 1-19.

Ehtesham, F. and Loghavi, M. 2012. Design development and field evaluation of a map-based variable rate granular fertilizer application control system. Agric Eng Int. CIGR Journal. 14(4): 255-261.

Flynt, T.O., Bovey, R.W., Meyer, R.E., Riley, T.E. and Baur, J.R. 1976.Granular Herbicide Applicator for Brush Control. Journal of Range Management. 29(5): 435-437.

Fulton, J.P., Shearer, S.A., Higgins, S.F., Darr, M.J. and Stombaugh, T.S. 2005. Rate
Response Assessment from Various Granular VRT Applicators. American Society of Agricultural Engineers. 48(6): 2095-2103.

Hoque, M.A., Wohab., Hossain, M.A., Saha, K.K. and Hassan, M.S. 2013. Improvement and evaluation of BARI USG applicator. Agric Eng Int CIGR Journal. 15(2): 87-94.

Jagvir, S., Mahal, G.S., Manes and Manjeet Singh. 2013. Development and evaluation of nitrogen (liquid Urea) applicatorfor straw mulched no-till wheat. Agric Eng Int:CIGRJournal. 15(4): 30-38.

Laukik, P.R., Smit, B.J. and Nitin, Y.M. 2013. Design, development and fabrication of agricultural pesticides sprayer with weeder. International Journal of Applied Research and Studies. 2:1-8.

Malekia, M.R., Ramona, H., Baerdemaekera, J.D. and Mouazenc, A.M. 2008. A study on the time response of a soil sensorbased variable rate granular fertiliser applicator. A text book of Bio systems Engineering. 160-166.

Mohammed, S.A., Desa, A., Othman, J., Samsuddin, S. and Norhisam, M. 2011. Evaluation of a Dual-Purpose Chemical Applicator for Paddy Fields. American Journal of Applied Sciences. 8 (4):362367.

Paul, E. Sumner. 2012. Granular Applicator Calibration Procedure. College of Agricultural and Environmental Sciences, University of Georgia Cooperative Extension. 1-4.

Rajesh, S. and Xiaoying, J. 2014. Urea Super Granule (USG) as Key Conductor in Agricultural Productivity Development in Bangladesh, Developing Country Studies. 4(6): 132-139.

\section{How to cite this article:}

Sai Srinivas, M., B. Raj Kiran, B. Sailaja and Krishna, M.M. 2017. Development of the Hand Operated Granular Applicator for Creeper Crops. Int.J.Curr.Microbiol.App.Sci. 6(12): 4015-4024. doi: https://doi.org/10.20546/ijcmas.2017.612.462 